\title{
(6) OPEN ACCESS \\ Does parenting help to explain socioeconomic inequalities in children's body mass index trajectories? Longitudinal analysis using the Growing Up in Scotland study
}

\author{
Alison Parkes, Helen Sweeting, Robert Young, Daniel Wight
}

\begin{abstract}
- Additional material is published online only. To view please visit the journal online (http://dx.doi.org/10.1136/jech2015-206616).

MRC/CSO Social and Public Health Sciences Unit, University of Glasgow, Glasgow, UK
\end{abstract}

\section{Correspondence to} Alison Parkes, MRC/CSO Social and Public Health Sciences Unit, University of Glasgow, Top floor, 200, Renfield Street, Glasgow G2 3QB, UK; Alison.parkes@glasgow.ac.uk

Received 7 September 2015 Revised 8 March 2016 Accepted 17 March 2016 Published Online First 7 April 2016

\begin{abstract}
Background Pathways leading to socioeconomic inequalities in young children's body mass index (BMI) are not well understood. This study examined whether parenting related to the physical and social context of children's food consumption helped to explain associations between maternal educational level and child BMI trajectory.
\end{abstract}

Methods The study used data from 2957 families in a nationally representative birth cohort study surveyed from 2004 to 2011, with child BMI z-score measured 3 times (46, 70 and 94 months). Latent growth curve models examined associations between maternal education and BMI z-score trajectory, exploring mediating effects of parenting (positive mealtime interaction, informal meal setting and child bedroom TV) and unhealthy child diet. Results After adjusting for maternal BMI, maternal education predicted increased inequality in child BMI z-score trajectory slope over the study period. The slope index of inequality coefficient for maternal education, that is, the change in z-score associated with the lowest relative to the highest maternal education level, was 0.17 , $p<0.001$. Indirect effects of lower maternal education on steeper BMI trajectory via parenting and/or unhealthy diet represented $89 \%$ of the total effect. Pathways via parenting and then unhealthy diet accounted for $68 \%$ of significant indirect pathways, with the remainder via unhealthy diet only. Bedroom TV was the most important parenting pathway, followed by informal meal setting. Conclusions Pathways via parenting helped to explain the emergence of inequalities in young children's BMI related to maternal education. Interventions targeting parental provision of child bedroom TV and informal meal setting might reduce these inequalities.

\section{BACKGROUND}

Parental socioeconomic position (SEP) is inversely associated with childhood obesity in high-income countries. A review found that parental education is the SEP indicator most strongly associated with childhood obesity, even after controlling for maternal body mass index (BMI). ${ }^{1}$ Inequalities in children's BMI according to maternal education appear after about 4 years of age and widen thereafter, ${ }^{2}{ }^{3}$ but pathways underlying the development of inequalities are not currently well understood. It is well known that children of lower SEP, like their parents, have higher fat and sugar intake. ${ }^{4}$ However, we have only fragmented knowledge of how socioeconomic variation in family life shapes children's diet, and how this may translate into socioeconomic variation in children's BMI. ${ }^{5}{ }^{6}$ This study addresses our gap in knowledge surrounding key influences, focusing on aspects of family life with young children likely to reflect important elements of parental choice and control, and which may be potentially modifiable. There has been much interest in parental feeding practices directly concerned with children's eating. ${ }^{7}$ Some practices vary according to parental SEP, but many do not appear strongly linked to children's BMI. ${ }^{6}$ Here, we are concerned with more general aspects of parental provision and behaviour, referred to collectively as 'parenting'. We select aspects of parenting related to the physical and social context of children's food consumption that have been identified elsewhere as being patterned according to parental SEP and associated with children's unhealthy diet and/or BMI. Our study aims to develop a more complete model for the emergence of SEP-related inequalities, constructing plausible pathways from parental SEP to child BMI trajectory via parenting and its effects on unhealthy diet, and assessing their likely importance.

Family mealtimes have been a primary focus of research interest in relation to children's diet and weight gain. Eating together is a less-established practice among lower SEP families, ${ }^{8}$ and might help explain inequalities in child weight gain. Nonetheless, while shared family meals have been linked to a healthy diet, ${ }^{9}$ reviews find associations between family meal frequency and childhood overweight are weak and inconsistent. ${ }^{9} 10$ Given these findings, and that simply knowing whether families eat together tells us little about family processes protecting against weight gain, ${ }^{11}$ it seems important to consider a broader range of contextual aspects of children's food consumption at home. One context already receiving considerable research attention is a TV-orientated home environment. Two aspects of this, eating meals while watching TV and the child having a TV in her/his bedroom, are more common among low SEP groups. ${ }^{12}{ }^{13}$ A large multinational European study of 2-9-year-olds found both factors were independently associated with a diet high in fats and sugars, and with overweight, over and above time spent watching TV. ${ }^{14}$ This suggests the possibility of two different dietary pathways to overweight arising from a TV-orientated context of food consumption, involving family mealtimes in front of a TV and the child snacking between meals while watching a bedroom TV. However, the extent to which 
TV's effects on children's diet translates into SEP-related BMI inequalities has not yet been established.

Other contextual aspects of family food consumption have been less extensively researched. There are indications that an informal mealtime setting - not being seated at a table-has associations with children's unhealthy diet ${ }^{15}$ and $\mathrm{BMI}^{16}$ that are independent of TV use at meals. In addition, the quality of social interaction at mealtimes is associated with parental regulation of children's eating habits. ${ }^{17}$ It has been linked to child BMI in one cross-sectional study, ${ }^{11}$ although another study taking greater account of mealtime setting found associations only with adult BMI. ${ }^{16}$ Lower socioeconomic groups are less likely to eat at a table, ${ }^{18}$ with fewer positive interactions at mealtimes (such as sharing feelings, discussing family events, joking) compared with high SEP groups. ${ }^{11}$ Again, it is not known how social variation in these parenting behaviours translates into SEP-related inequalities in children's BMI.

This study uses a nationally representative cohort sample to examine associations between maternal education and children's BMI trajectory over a 4-year period, from 46 to 94 months: a critical developmental period when SEP inequalities are likely to emerge and increase. ${ }^{2}{ }^{3}$ It explores whether variation in BMI trajectory according to mothers' education is mediated via the effect of parenting on children's unhealthy diet. We investigate the following hypotheses:

- Lower maternal education will be associated with three aspects of parenting: less positive mealtime interaction, an informal mealtime setting (watching TV, and/or sitting away from a dining area) and bedroom TV;

- All aspects of parenting will have positive associations with unhealthy child diet;

- Unhealthy child diet will be associated with a steeper BMI trajectory, as evidenced in recent longitudinal research. ${ }^{19}$

\section{METHODS}

\section{Data set}

Data were from the first birth cohort of the Growing Up in Scotland study, a nationally representative cohort of families with children born between June 2004 and May 2005. Details of the sampling framework are provided elsewhere. ${ }^{20}$ Families were first interviewed $(\mathrm{N}=5217)$ when children were 10 months old, and followed up annually until 70 months and then again at 94 months. Data collection was subject to medical ethical review by the Scotland 'A' MREC committee.

\section{Outcome measure: child BMI z-score}

Height and weight measurements were obtained by trained researchers when the child was 46, 70 and 94 months old. BMI (weight $(\mathrm{kg}) /$ height $(\mathrm{m})^{2}$ ) was calculated, and standardised BMI z-scores were derived from 1990 British growth reference charts. ${ }^{21}$ Measures three SDs or more from the mean were treated as potentially unreliable, and recoded as missing $(\mathrm{N}=20$ at 46 months, and $\mathrm{N}=24$ at 70 and 94 months).

\section{Main predictor: maternal educational level}

This was based on maternal reports and classified into five groups, using the Scottish Credit and Qualifications Framework. ${ }^{i}$ These were: (1) degree-level qualifications; (2)

iSee http://www.scqf.org.uk/TheFramework/. At the time of the survey, higher and standard grades were the respective Scottish equivalents of advanced level and general certificate of education qualifications obtained in other parts of the UK (England, Wales and Northern Ireland). advanced vocational qualifications (higher national certificate or equivalent); (3) upper level secondary school qualifications, leading to university entry (higher or equivalent); (4) lower level secondary school qualifications (standard grades or equivalent); (5) no qualifications. A slope index of inequality ${ }^{22}$ (SSI) in maternal education was calculated, with zero representing the highest ranking SEP and one the lowest possible SEP rank.

\section{Potential mediators}

A latent variable approach was used to model mediators, offering advantages in terms of accurate estimation of indirect effects and allowance for non-normality. ${ }^{23}$ Unhealthy diet was measured at 58 months using six indicators: (1) skipping breakfast on a typical day; number of different types of (2) vegetable and (3) fruit consumed the previous day; and how often the child consumed (4) sweets and chocolates; (5) crisps; and (6) soft drinks, excluding diet or sugar-free drinks. Response options were: skipping breakfast, no (0), yes (1); vegetable and fruit consumption open-ended response (range 0-8); consumption of sweets, crisps and soft drinks, eight-point scale from (1) never to (8) more than once a day. Two indicators of positive mealtime interaction represented mothers' views at 58 months on whether 'mealtimes are enjoyable for everyone' and 'mealtimes give us time to talk to each other'; with responses from (1) never to (4) mostly. Indicators of informal mealtime setting included eating a main meal watching TV (58 months); and the room where the child typically ate a main meal (22 and 58 months). Eating while watching TV was coded from (1) never to (4) often. For room information, seven response options were grouped into (0) rooms with a dining or food preparation area (kitchen, dining room, combined living/dining room) or (1) those without a dining area (living room, bedroom, other room). Child bedroom TV was measured using two indicators at 46 and 58 months, coded as (0) 'no' or (1) 'yes'.

\section{Covariates}

These included child gender, exact age in months at first time point of data collection (mean age 46 months), maternal ethnic group (White or Minority) and maternal BMI at child aged 70 months.

\section{Analysis}

In total, 3196 families were interviewed at all relevant time points from 10 to 94 months. The analysis was restricted to 2957 cases where the child was a singleton birth, the natural mother was interviewed on all occasions and child BMI information was available at one or more measurement points.

Initial visualisation of the data suggested a linear decline in BMI z-scores over the study period. A linear latent growth curve model of mean child BMI was constructed using Mplus V.7.3, ${ }^{24}$ and the association between maternal education and BMI trajectory was explored, before and after adjusting for maternal BMI. Missing data were handled using Full Information Maximum Likelihood.

A path model was constructed to examine mediation from maternal education to child BMI trajectory via parenting and then child unhealthy diet, as well as via unhealthy diet only. We also included alternative pathways via parenting directly to child BMI (ie, not via unhealthy diet), as well as allowing for a direct effect of maternal education on child BMI (ie, not via any mediator). Mediation was assessed using the Mplus Model Indirect function, which decomposes the total effect of maternal education into direct and indirect effects. Bias-corrected bootstrapped 
Table 1 Child obesity and risk factors for the total sample, and by maternal educational level

\begin{tabular}{|c|c|c|c|c|c|c|}
\hline & \multirow[b]{2}{*}{ Total sample } & \multicolumn{5}{|c|}{ Maternal education level } \\
\hline & & $\begin{array}{l}\text { Degree } \\
\text { level }\end{array}$ & $\begin{array}{l}\text { Advanced } \\
\text { vocational }\end{array}$ & $\begin{array}{l}\text { Upper level } \\
\text { secondary school }\end{array}$ & $\begin{array}{l}\text { Lower level } \\
\text { secondary school }\end{array}$ & $\begin{array}{l}\text { No } \\
\text { qualifications }\end{array}$ \\
\hline$N$ unweighted (weighted) & 2957 & $972(770)$ & $402(367)$ & $658(645)$ & 706 (832) & $152(242)$ \\
\hline Child obesity (46 months) & 11.1 & 8.5 & 7.9 & 14.3 & 10.5 & 17.2 \\
\hline Child obesity (70 months) & 9.9 & 6.1 & 8.7 & 11.9 & 11.5 & 13.2 \\
\hline Child obesity (94 months) & 13.1 & 8.2 & 11.2 & 15.5 & 14.8 & 19.1 \\
\hline Child female gender & 48.4 & 47.7 & 50.5 & 47.8 & 48.8 & 45.8 \\
\hline Maternal minority ethnic group & 3.0 & 3.4 & 3.4 & 2.8 & 1.8 & 4.1 \\
\hline Maternal obesity & 16.1 & 13.1 & 14.8 & 16.9 & 16.6 & 24.0 \\
\hline Family income-lowest quintile & 24.7 & 4.4 & 17.6 & 21.0 & 39.8 & 59.1 \\
\hline Area deprivation-highest quintile & 23.4 & 8.1 & 21.2 & 21.8 & 31.4 & 52.7 \\
\hline \multicolumn{7}{|l|}{ Unhealthy diet } \\
\hline Sweets/chocolate (58 months) & $5.99(0.04)$ & $5.60(0.05)$ & $5.91(0.08)$ & $5.95(0.06)$ & $6.26(0.06)$ & $6.56(0.13)$ \\
\hline Crisps (58 months) & $4.97(0.04)$ & $4.39(0.05)$ & $4.95(0.08)$ & $4.96(0.06)$ & $5.29(0.07)$ & $5.76(0.16)$ \\
\hline Soft drinks (58 months) & $4.45(0.10)$ & $3.74(0.12)$ & $4.50(0.17)$ & $4.56(0.15)$ & $4.84(0.16)$ & $5.07(0.28)$ \\
\hline Vegetables (58 months) & $1.60(0.03)$ & $1.98(0.05)$ & $1.71(0.07)$ & $1.59(0.05)$ & $1.33(0.05)$ & $1.15(0.11)$ \\
\hline Fruit (58 months) & $1.96(0.03)$ & $2.23(0.04)$ & $2.10(0.06)$ & $2.03(0.05)$ & $1.69(0.05)$ & $1.58(0.09)$ \\
\hline Skip breakfast (58 months) & 4.8 & 1.1 & 2.7 & 3.1 & 5.3 & 22.7 \\
\hline \multicolumn{7}{|l|}{ Informal meal setting } \\
\hline Main meal in non-dining area (22 months) & 36.2 & 17.0 & 30.2 & 38.0 & 48.8 & 65.4 \\
\hline Main meal in non-dining area (58 months) & 32.2 & 13.5 & 27.1 & 33.3 & 45.2 & 64.4 \\
\hline Eat main meal watching TV (58 months) & $2.20(0.03)$ & $1.83(0.04)$ & $2.16(0.06)$ & $2.21(0.05)$ & $2.38(0.05)$ & $2.83(0.10)$ \\
\hline \multicolumn{7}{|l|}{ Positive mealtime social interaction } \\
\hline Mealtimes are enjoyable (58 months) & $3.27(0.02)$ & $3.34(0.03)$ & $3.34(0.05)$ & $3.28(0.04)$ & $3.23(0.03)$ & $3.07(0.09)$ \\
\hline Mealtimes give us time to talk (58 months) & $3.37(0.02)$ & $3.49(0.03)$ & $3.44(0.04)$ & $3.46(0.03)$ & $3.27(0.04)$ & $3.03(0.09)$ \\
\hline \multicolumn{7}{|l|}{ Bedroom TV } \\
\hline Bedroom TV (46 months) & 45.8 & 14.8 & 43.0 & 50.2 & 63.1 & 81.1 \\
\hline Bedroom TV (58 months) & 51.6 & 18.8 & 52.2 & 56.5 & 69.5 & 83.5 \\
\hline
\end{tabular}

estimates were produced following recommended practice. ${ }^{25}$ As software constraints did not permit the complex survey design and weights in this model, a sensitivity analysis used complex survey features and saved factor scores of the latent mediator variables.

\section{RESULTS}

Information on child obesity levels and risk factors is provided in table 1 . With the exception of child gender and maternal ethnic group, significant differences were found for all measures according to the level of maternal education.

Obesity levels in the sample ( $\geq 95$ th BMI centile, according to British growth charts) increased slightly from $11 \%$ at 46 months to $13 \%$ at 94 months, ${ }^{\text {ii }}$ although mean BMI z-score fell from 0.45 (95\% CI 0.40 to 0.49$)$ to $0.36(0.31,0.41)$. The z-score decrease is consistent with declining raw BMI scores across this age range in other UK studies, ${ }^{26}{ }^{27}$ together with flat corresponding sections of 1990 BMI growth curves. ${ }^{28}$ Figure 1 shows mean child BMI z-score at each time point according to level of maternal education, and indicates increasing inequalities in mean BMI z-score over the 4-year period. At 46 months, there were few clear differences between education groups (only one contrast, children of mothers with degree-level

${ }^{i i}$ No gender difference was observed. qualifications vs those with upper level school qualifications, was statistically significant to $\mathrm{p}<0.05$ ). By 94 months, children whose mothers had degree-level education had significantly lower mean BMI z-scores than all other groups except mothers with advanced vocational qualifications. BMI z-scores regressed on maternal education ranked scores (SSI) confirm this picture of increasing inequalities (coefficients $0.10, \mathrm{p}=0.210 ; 0.15$, $\mathrm{p}=0.040$ and $0.27, \mathrm{p}=0.001$ at 46,70 and 94 months, respectively).

A latent growth model of BMI z-score had a mean intercept of 0.45 (at 46 months, $\mathrm{p}<0.001$ ) and a negative slope of -0.06 (representing the change over the entire 46-94-month period, $\mathrm{p}<0.001)$. The SSI for lower maternal education was not associated with child BMI intercept at 46 months (table 2), but it had a positive association with BMI slope even after adjusting for maternal BMI (coefficient 0.17, representing the change in child BMI z-score over the entire study period associated with the lowest, relative to the highest, maternal education level). There was no statistically significant $(p<0.05)$ interaction between maternal BMI and education in this model. Additional analyses found no association for family income or area deprivation with child BMI intercept or slope after adjustment for maternal BMI (see online supplementary file S1).

A measurement model was constructed to assess the four latent constructs (unhealthy diet, informal meal setting, positive mealtime interaction and bedroom TV) used as potential mediators of associations between maternal education and child BMI 
Figure 1 Child BMI at ages 46, 70 and 94 months according to maternal educational level. Note: bars show 95\% Cls. BMI, body mass index.

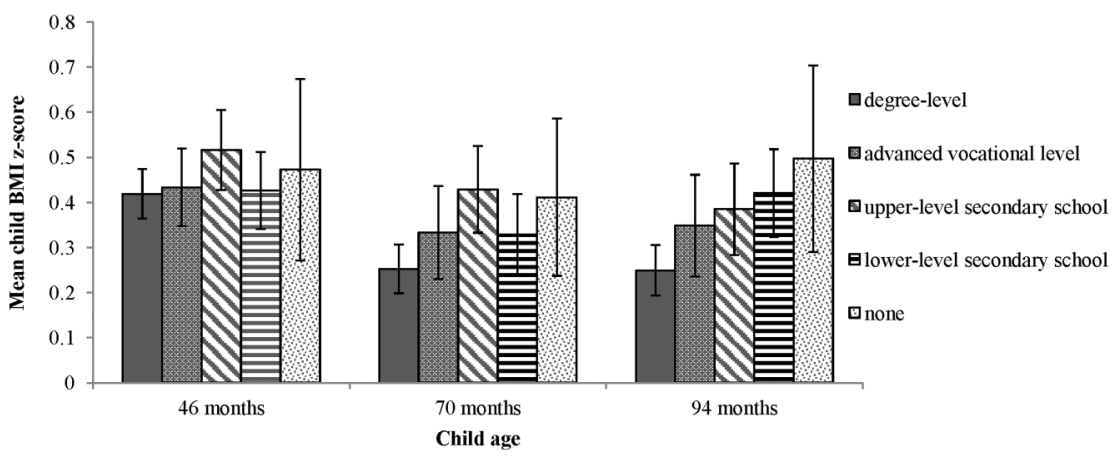

trajectory. Two indicators of unhealthy diet (soft drink and fruit consumption) with loadings $<0.4$ were dropped. Further details of this model are provided in an online supplementary file S2. Figure 2 shows the results of the path model used to explore associations between maternal education and child BMI slope via the four latent constructs. For simplicity, this figure is restricted to statistically significant pathways $(p<0.05)$, and to aid comparability, standardised estimates of coefficients have been provided. All significant pathways from parenting measures to child BMI were via unhealthy diet. Lower maternal education predicted less positive mealtime interaction $(-0.14)$, but greater likelihood of informal mealtime setting $(0.37)$ and bedroom TV (0.48). In turn, positive mealtime interaction was negatively associated with unhealthy diet $(-0.19)$, while informal mealtime and bedroom TV both had positive associations ( 0.22 and 0.46 , respectively). There was also a positive effect from lower maternal education to unhealthy diet, not via parenting (0.14). Finally, unhealthy diet had a positive association with child BMI slope (0.17).

Estimates of indirect, direct and total effects of lower maternal education on child BMI slope are shown in table 3.

The indirect effects of lower maternal education via all mediators (0.16) comprised $89 \%$ of the total effect of maternal education on BMI slope. Pathways to BMI slope from maternal education through parenting and then unhealthy diet accounted for $68 \%$ of the statistically significant indirect pathways. The main indirect pathway involving parenting was via the effect of bedroom TV, with smaller effects of informal meal setting and less positive mealtime interaction.

A sensitivity analysis to allow for the complex survey design was conducted, using mediator factor scores to replace latent variables (see online supplementary file S3). The relative magnitude of pathways was similar to findings in table 3 , although as

Table 2 Associations between lower maternal education and child BMI trajectory, $\mathrm{N}=2957$

\begin{tabular}{|c|c|c|c|c|}
\hline & \multicolumn{2}{|c|}{$\begin{array}{l}\text { Intercept } \\
\text { (46 months) }\end{array}$} & \multicolumn{2}{|c|}{ Slope (46-94 months) } \\
\hline & $\boldsymbol{\beta}$ (SE) & p Value & $\boldsymbol{\beta}$ (SE) & p Value \\
\hline $\begin{array}{l}\text { Stage } 1-\text { not adjusted for } \\
\text { maternal BMI }\end{array}$ & $0.07(0.08)$ & 0.365 & $0.20(0.05)$ & $<0.001$ \\
\hline $\begin{array}{l}\text { Stage } 2 \text {-adjusted for } \\
\text { maternal BMI }\end{array}$ & $0.03(0.08)$ & 0.749 & $0.17(0.05)$ & 0.001 \\
\hline \multicolumn{5}{|c|}{$\begin{array}{l}\text { Models adjust for child gender and exact age at BMI measurements, maternal } \\
\text { minority ethnic status. Model fit statistics: comparative fit index } 0.99 \text {, root mean } \\
\text { square error of approximation } 0.05 \text {. Figures show coefficients and SEs, and represent } \\
\text { the effect of the slope index of inequality for maternal education, which compares } \\
\text { lowest with highest education level. } \\
\text { BMI, body mass index. }\end{array}$} \\
\hline
\end{tabular}

expected with the use of directly observed mediators ${ }^{23}$ the total indirect effect was reduced.

\section{DISCUSSION}

Our findings confirm other research suggesting the emergence and growth of inequalities in mean child BMI trajectory relating to maternal education after about 4 years of age, ${ }^{2} 3$ and extend the mainly cross-sectional evidence base. ${ }^{13}$ Pathways leading to the emergence of SEP inequalities in young children's BMI trajectory have received little attention in the literature to date. This is the first study to suggest that a substantial part of these inequalities may be understood in terms of the effect of parenting related to the physical and social context of food consumption on children's unhealthy diet.

Two indirect pathways via informal meal setting and bedroom TV suggest the likely influence of TV on children's eating behaviour. TV food advertising acts as a direct stimulus to consumption of unhealthy snacks. ${ }^{29}$ More generally, watching TV while eating interferes with normal habituation to food cues, delays feelings of satiety and reduces memory of food consumed. ${ }^{30}$ Our informal meal setting measure included eating main meals in front of a TV, and echoes other research finding a link between this behaviour and increased child BMI in North America and Europe. ${ }^{12} 1431$ A pathway to BMI from bedroom TV via unhealthy diet was also suggested in one of these European studies: ${ }^{14}$ both this and longitudinal US research on 10-14-year-olds ${ }^{32}$ found effects of eating main meals while watching TV and bedroom TV on BMI, even after controlling for hours of TV. This appears to tally with our own finding of no significant direct path from our two TV-related mediators to child BMI, as would be expected if the effect was through more sedentary behaviour or less sleep. Since few children in our study ate their main meal in their bedroom, our finding for a path from bedroom TV to BMI via unhealthy diet may reflect greater consumption of energy-dense snacks while watching TV. $^{12} 14{ }^{33}$ Like others, ${ }^{32}$ we speculate that bedroom TV might directly stimulate snack consumption, via the child selecting TV programming incorporating greater exposure to unhealthy food advertising. Additional effects of bedroom TV on greater consumption of energy-dense foods might relate to lower parental control of bedroom activities, as research has shown weaker links between authoritative parenting and sugary drink consumption among children with a bedroom TV. ${ }^{34}$ Bedroom TV might also delay children's sleep onset, which has been linked to poor diet quality and $\mathrm{BMI},{ }^{35}$ although causal relationships between TV, sleep and diet remain uncertain. We were unable to explore other factors that may be confounded with bedroom TV and unhealthy diet, such as family physical activity and access to recreational facilities. 
Figure 2 Path model of associations between maternal education and BMI slope via parenting and unhealthy diet, $\mathrm{N}=2957$. Note: model shows significant pathways only, with standardised coefficients $\left({ }^{* *} p<0.01\right.$, $* * * p<0.001)$. Model adjusts for child gender and exact age at first BMI measure, maternal BMI and minority ethnic status. BMI, body mass index; mo, months.

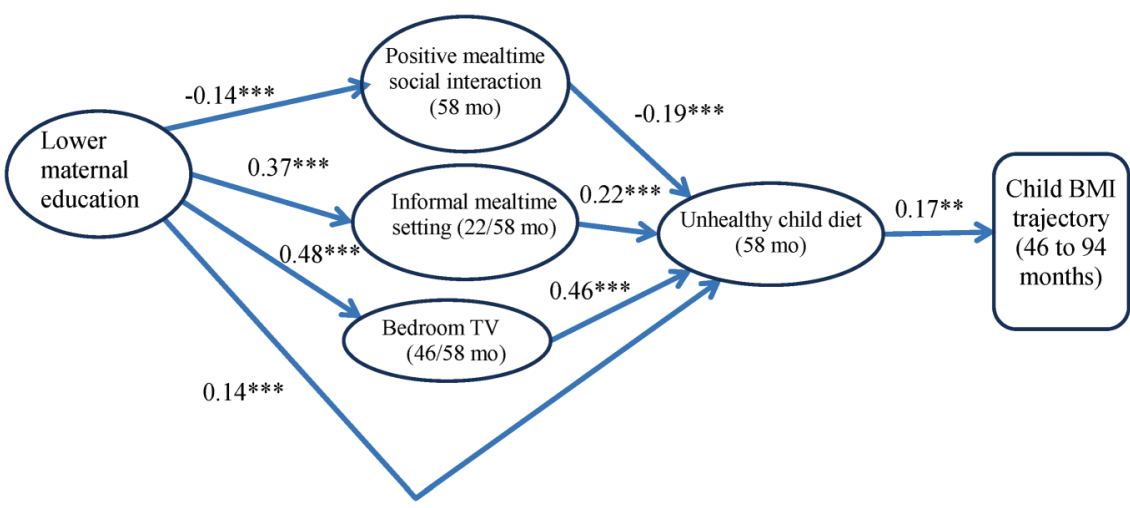

Additional pathways less directly related to TV use are suggested by our study, involving mealtime setting and social interaction. The role of informal setting, away from a dining area, is echoed by cross-sectional research linking eating in the kitchen or dining room to lower child BMI. ${ }^{16}$ Our effect of setting might be confounded with omitted variables such as material hardship, although BMI inequalities were associated with neither income nor area deprivation. Effects may relate to lower parental monitoring of food intake and/or less insistence on eating at particular times. ${ }^{36}$ We also found a small pathway via less positive social interaction, in agreement with another study associating positive mealtime communication with lower child $\mathrm{BMI},{ }^{11}$ and supporting the idea that positive parental communication at mealtimes promotes healthy eating. ${ }^{36}$ Nonetheless, it is not possible to rule out other aspects of parenting that may be confounded with this pathway.

\section{Limitations}

Although suggested pathways appear plausible from what is known elsewhere, detailed elements require further investigation to substantiate causal mechanisms. Part of the effect of maternal education remained unaccounted for by our parenting mediators, and additional pathways underlying the development of inequalities in BMI trajectory (eg, via parental modelling of diet, or feeding style) require investigation. Our study has several other limitations. We only had child BMI information

Table 3 Direct and indirect effects of lower maternal education on child BMI slope

\begin{tabular}{lcc}
\hline & Estimate $(95 \% \mathrm{Cl})$ & $\mathbf{p}$ Value \\
\hline Total & $0.18(0.07$ to 0.28$)$ & 0.001 \\
Total indirect & $0.16(0.07$ to 0.25$)$ & 0.001 \\
Specific indirect effects & & \\
$\quad$ Via unhealthy diet & $0.06(0.02$ to 0.12$)$ & 0.019 \\
$\quad$ Via informal setting & $0.02(-0.05$ to 0.07$)$ & 0.561 \\
$\quad$ Via less positive mealtime interaction & $-0.02(-0.05$ to 0.00$)$ & 0.066 \\
$\quad$ Via bedroom TV & $-0.03(-0.15$ to 0.08$)$ & 0.559 \\
$\quad$ Via informal setting and unhealthy diet & $0.03(0.01$ to 0.07$)$ & 0.011 \\
$\quad$ Via less positive mealtime interaction and & $0.01(0.00$ to 0.03$)$ & 0.032 \\
$\quad$ unhealthy diet & & \\
$\quad$ Via bedroom TV and unhealthy diet & $0.09(0.03$ to 0.16$)$ & 0.005 \\
Direct effect & $0.02(-0.13$ to 0.16$)$ & 0.821 \\
\hline
\end{tabular}

Model as for figure 2. Unlike figure 2, this table shows unstandardised estimates. Model adjusts for child gender and exact age at first BMI measure, maternal BMI and minority ethnic status.

BMI, body mass index. for three time points, restricting us to a linear latent growth curve model; and modelling maternal education as a slope index assumed a linear relationship with BMI. With the exception of height and weight measurements for child and mother, we relied on maternal reports. The Growing Up in Scotland study is a multipurpose study: thus, many measures are indicative, rather than comprehensive. Maternal BMI was not measured until the child was aged 70 months: future studies should incorporate earlier measures of maternal and child BMI over a longer period. Strengths of the study include use of a large, longitudinal sample that was nationally representative at baseline, incorporating weights to compensate for differential attrition, and use of a latent variable mediator approach. ${ }^{23}$

In conjunction with the widespread phenomenon of high rates of childhood obesity over recent decades, there is evidence for growing socioeconomic inequalities. ${ }^{37}$ To date, there is only scanty evidence for the effectiveness of interventions

\section{What is already known on this subject}

- Inequalities in body mass index (BMI) relating to maternal educational level start to emerge when children are about 4 years old.

- Pathways underlying the development of these inequalities are not well understood.

\section{What this study adds}

- The study modelled pathways from maternal education to young children's BMI trajectory via parenting and unhealthy diet. It focused on three aspects of parenting more commonly reported by mothers with lower, rather than higher, education levels: provision of bedroom TV for the child; informal main meal setting and less positive mealtime social interaction.

- A substantial part of the inequalities in child BMI trajectory associated with maternal education could be interpreted in terms of pathways from lower maternal education via these three aspects of parenting to unhealthy child diet, and in turn to child BMI trajectory.

- Interventions targeting these three aspects of family life might reduce inequalities in young children's BMI trajectories associated with maternal education. 
designed to reduce these inequalities, although there are indications that restricting TV time could be effective. ${ }^{39}$ While further work on mealtime social interactions is needed, to capture more detailed information, our findings suggest aspects of parenting, especially provision of bedroom TV and informal meal setting for children, may be suitable intervention targets.

Acknowledgements This research was supported by UK Medical Research Council grants MC_UU_12017/11, MC_UU_12017/12, MC_UU_12017/9 and MC_UU_12017/3. The authors are grateful to all the families who participated in the Growing Up in Scotland (GUS) study, and thank Paul Bradshaw and the GUS survey team at ScotCen Social Research for data collection. The GUS study is funded by the Scottish Government.

Contributors AP conceived the idea for this study, carried out the analysis of the data and wrote the first draft. HS, RY and DW contributed to the development of the final manuscript.

Funding Medical Research Council, 10.13039/501100000265, MC_UU_12017/ 11, MC_UU_12017/12, MC_UU_12017/3, MC_UU_12017/9.

Disclaimer The funder had no part in the design and conduct of the study; collection, management, analysis and interpretation of the data; and preparation, review or approval of the manuscript.

Competing interests None declared.

Ethics approval Scotland 'A' MREC committee.

Provenance and peer review Not commissioned; externally peer reviewed.

Data sharing statement Data from the Growing Up in Scotland study are freely available from the UK Data Archive.

Open Access This is an Open Access article distributed in accordance with the terms of the Creative Commons Attribution (CC BY 4.0) license, which permits others to distribute, remix, adapt and build upon this work, for commercial use, provided the original work is properly cited. See: http://creativecommons.org/licenses/ by/4.0/

\section{REFERENCES}

1 Shrewsbury V, Wardle J. Socioeconomic status and adiposity in childhood: a systematic review of cross-sectional studies 1990-2005. Obesity (Silver Spring) 2008; 16:275-84.

2 Howe LD, Tilling K, Galobardes B, et al. Socioeconomic disparities in trajectories of adiposity across childhood. Int J Pediatr Obes 2011;6:E144-53.

3 Balistreri KS, Van Hook J. Trajectories of overweight among US school children: a focus on social and economic characteristics. Matern Child Health J 2011;15:610-19.

4 Patrick $H$, Nicklas TA. A review of family and social determinants of children's eating patterns and diet quality. J Am Coll Nutr 2005;24:83-92.

5 Johnson F, Pratt M, Wardle J. Socio-economic status and obesity in childhood. In: Aznar LAM, Pigeot I, Ahrens W, eds. Epidemiology of obesity in children and adolescents: prevalence and etiology. Springer, 2011:377-90.

6 Russell CG, Taki S, Laws R, et al. Effects of parent and child behaviours on overweight and obesity in infants and young children from disadvantaged backgrounds: systematic review with narrative synthesis. BMC Public Health 2016;16:151.

7 Gevers DW, Kremers SP, de Vries NK, et al. Clarifying concepts of food parenting practices. A Delphi study with an application to snacking behavior. Appetite 2014:79:51-7.

8 Larson N, MacLehose R, Fulkerson JA, et al. Eating breakfast and dinner together as a family: associations with sociodemographic characteristics and implications for diet quality and weight status. J Acad Nutr Diet 2013;113:1601-9.

9 Hammons AJ, Fiese BH. Is frequency of shared family meals related to the nutritional health of children and adolescents? Pediatrics 2011:127:E1565-74.

10 Valdes J, Rodriguez-Artalejo F, Aguilar L, et al. Frequency of family meals and childhood overweight: a systematic review. Pediatr Obes 2013:8:e1-e13.

11 Fiese BH, Hammons A, Grigsby-Toussaint D. Family mealtimes: a contextual approach to understanding childhood obesity. Econ Hum Biol 2012;10:365-74.

12 Dubois L, Farmer A, Girard M, et al. Social factors and television use during meals and snacks is associated with higher BMI among pre-school children. Public Health Nutr 2008;11:1267-79.

13 Christakis DA, Ebee BE, Rivara FP, et al. Television, video, and computer game usage in children under 11 years of age. J Pediatr 2004;145:652-6.
14 Lissner L, Lanfer A, Gwozdz W, et al. Television habits in relation to overweight, diet and taste preferences in European children: the IDEFICS study. Eur J Epidemiol 2012;27:705-15.

15 Mak TN, Prynne CJ, Cole D, et al. Assessing eating context and fruit and vegetable consumption in children: new methods using food diaries in the UK National Diet and Nutrition Survey Rolling Programme. Int I Behav Nutr Phys Act 2012:9:126.

16 Wansink B, van Kleef E. Dinner rituals that correlate with child and adult BMI. Obesity (Silver Spring) 2014:22:E91-5.

17 Fiese $\mathrm{BH}$, Foley $\mathrm{KP}$, Spagnola M. Routine and ritual elements in family mealtimes: contexts for child well-being and family identity. New Dir Child Adolesc Dev 2006;2006:67-89.

18 Attorp A, Scott JE, Yew AC, et al. Associations between socioeconomic, parental and home environment factors and fruit and vegetable consumption of children in grades five and six in British Columbia, Canada. BMC Public Health 2014;14:150.

19 Millar L, Rowland B, Nichols $\mathrm{M}$, et al. Relationship between raised BMI and sugar sweetened beverage and high fat food consumption among children. Obesity (Silver Spring) 2014; 22: E96-E103.

20 Bradshaw P, Tipping S, Marryat L, et al. Growing Up in Scotland sweep 1-2005 user guide. Edinburgh: Scottish Centre for Social Research, 2007.

21 Pan H, Cole T, LMS growth. Medical Research Council, United Kingdom, 2002-07. South Shields: Harlow Printing Limited; 2008. http://www.healthforallchildren.com/ shop-base/shop/software/lmsgrowth/

22 Adams J. Re: Low A, low, A. Measuring the gap: quantifying and comparing local health inequalities. J Public Health (Oxf) 2004;26:388-95.

23 Muthén B, Asparouhov T. Causal Effects in Mediation Modeling: An Introduction With Applications to Latent Variables. Structural Equation Modeling: A Multidisciplinary Journal 2015;22:12-23.

24 Muthén LK, Muthén BO. Mplus user's guide. 7th edn. Los Angeles, CA: Muthén \& Muthén, 1998-2012.

25 MacKinnon DP, Lockwood CM, Williams J. Confidence limits for the indirect effect: distribution of the product and resampling methods. Multivariate Behav Res 2004;39:99-99.

26 Howe LD, Tilling $K$, Benfield $L$, et al. Changes in ponderal index and body mass index across childhood and their associations with fat mass and cardiovascular risk factors at age 15. PLOS ONE 2010;5:e15186.

27 Martinson ML, McLanahan S, Brooks-Gunn J. Variation in child body mass index patterns by race/ethnicity and maternal nativity status in the United States and England. Matern Child Health J 2015;19:373-80.

28 Cole TJ, Freeman JV, Preece MA. Body mass index reference curves for the UK, 1990. Arch Dis Child 1995;73:25-9.

29 Harris JL, Bargh JA, Brownell KD. Priming effects of television food advertising on eating behavior. Health Psychol 2009;28:404-13.

30 Marsh S, Mhurchu CN, Maddson R. The non-advertising effects of screen-based sedentary activities on acute eating behaviours in children, adolescents, and young adults. A systematic review. Appetite 2013;71:259-73.

31 Vik FN, Bjornara HB, Overby NC, et al. Associations between eating meals, watching TV while eating meals and weight status among children, ages 10-12 years in eight European countries: the ENERGY cross-sectional study. Int I Behav Nutr Phys Act 2013;10:58.

32 Gilbert-Diamond D, Li Z, Adachi-Mejia AM, et al. Association of a television in the bedroom with increased adiposity gain in a nationally representative sample of children and adolescents. JAMA Pediatr 2014;168:427-34

33 Lipsky LM, lannotti RJ. Associations of television viewing with eating behaviors in the 2009 health behaviour in school-aged children study. Arch Pediatr Adolesc Med 2012;166:465-72.

34 Schwartz MB, Gilstad-Hayden K, Henderson KE, et al. The relationship between parental behaviors and children's sugary drink consumption is moderated by a television in the child's bedroom. Child Obes 2015;11:560-8.

35 Golley RK, Maher CA, Matricciani L, et al. Sleep duration or bedtime? Exploring the association between sleep timing behaviour, diet and BMI in children and adolescents. Int J Obes (Lond) 2013;37: 546-51.

36 Hendy HM, Williams KE, Camise TS, et al. The Parent Mealtime Action Scale (PMAS). Development and association with children's diet and weight. Appetite 2009:52:328-39.

37 Frederick CB, Snellman K, Putnam RD. Increasing socioeconomic disparities in adolescent obesity. Proc Natl Acad Sci USA 2014;111:1338-42.

38 Stamatakis E, Wardle J, Cole TJ. Childhood obesity and overweight prevalence trends in England: evidence for growing socioeconomic disparities. Int J Obes (Lond) 2010:34:41-7.

39 Hillier-Brown FC, Bambra CL, Cairns JM, et al. A systematic review of the effectiveness of individual, community and societal level interventions at reducing socioeconomic inequalities in obesity amongst children. BMC Public Health 2014; 14:834. 